\title{
Resenha: Traduzir a canção
}

\author{
Heloísa Pezza Cintrão*
}

LOW, Peter. Translating Song. Lyrics and Texts. London, New York: Routledge, 2017. 132 p. ISBN: 978-1-138-64179-2

Translating Song apresenta-se como guia prático que visa a contribuir para melhor qualidade da tradução de canções:

Este é um livro de "como fazer". À diferença de algumas discussões existentes sobre tradução de canções, seu foco não é descrever e analisar como traduções e adaptações de música vocal foram realizadas no passado, mas sugerir estratégias e táticas para fazê-lo bem no futuro. Contudo, tais prescrições não podem ser dogmáticas. Por vezes, a prescrição soa mais como um: "eis algumas boas perguntas a fazer para si mesmo" ${ }^{1}$. (p. 3 )

Peter Low propõe-se orientar tradutores em melhores práticas na tradução de canções dos mais variados gêneros (de óperas a canções populares) e para diferentes finalidades (como libreto, supratitulação, encartes de discos), dedicando maior espaço à finalidade considerada mais desafiadora: traduções efetivamente “cantáveis” na outra língua.

A visada prática é previsível nos volumes dessa coleção da Routledge, Translation Practices Explained, dirigida a um público de tradutores profissionais e aprendizes, visando cobrir variados campos, em especial "áreas de atuação profissional em que as demandas do mercado de trabalho vêm

*Universidade de São Paulo. Professora de Tradução na Área de Espanhol do Departamento de Letras Modernas, credenciada no Programa de Pós-Graduação em Língua Espanhola e Literaturas Espanhola e Hispano-Americana e no Programa de Pós-Graduação em Estudos da Tradução da FFLCH USP.

${ }^{1}$ As traduções de trechos do livro para o português são minhas. 
crescendo" ${ }^{2}$. Em geral, os autores da coleção atuam como tradutores e/ou professores de tradução no campo sobre o qual escrevem, e dirigem-se em linguagem acessível a um público não necessariamente familiarizado com os Estudos da Tradução. Muitas vezes, os livros nasceram de cursos ministrados em universidades.

O autor de Translating Song, além de professor na Universidade de Canterbury, Nova Zelândia, tem ampla experiência prática como tradutor de música vocal: "disponibilizou mais de 150 traduções no LiederNet Archive (www.lieder.net/lieder), supralegendou seis óperas e elaborou traduções cantáveis para dezenas de canções, tanto clássicas como populares". Tem textos em coletâneas sobre tradução e música, por ex., capítulo no livro Song and Significance, organizado por Dinda Gorlée (2005), e artigo no número especial da revista The Translator sobre Tradução e Música, editado por Şebnem Susam-Sarajeva (2008), em anos nos quais livros ou números de revistas tratando exclusivamente desse campo eram ainda mais escassos do que atualmente. Em boa parte, Translating Song resulta de reunião, reelaboração e aprofundamento desses textos anteriormente publicados de forma esparsa, o que se explicita nos capítulos correspondentes.

Tem sete capítulos, com propostas de "princípios gerais" e táticas aplicáveis para traduzir canções entre quaisquer pares de línguas. Vários exemplos cobrem uma ampla gama de casos em que há "vozes cantando palavras" (p. 5), em diversos gêneros de canção. O primeiro capítulo é introdutório; o segundo trata de dificuldades típicas de compreensão da letra; o terceiro aborda diversas finalidades para as quais uma canção pode ser traduzida; o quarto focaliza dificuldades na fase de reelaboração da letra em outra língua; os capítulos 5 e 6 focalizam a tradução cantável, desenvolvendo a "abordagem do pentlato" (criada pelo autor); o capítulo 7 defende a necessidade de distinguir entre traduções, adaptações e mera "substituição de texto", nas traduções cantáveis, desenvolvendo uma proposta de como

\footnotetext{
${ }^{2}$ Para mais detalhes da coleção Translation Practices Explained, o catálogo completo pode ser consultado em <https://www.routledge.com/Translation-Practices-Explained/bookseries/TPE>. Acesso em 20/11/2018.
} 
fazer essa diferenciação. Ao final de cada capítulo há alguns exercícios práticos. Referências bibliográficas e sugestões de leituras suplementares aparecem ao final de cada capítulo. As páginas finais trazem um glossário e um índice remissivo. A seguir, o conteúdo dos capítulos em mais detalhe:

Cap. 1, "Introduction: song in human culture". Apresenta premissas que convergem para a de que "vale a pena traduzir letras de canções". Destaca a relevância cultural e afetiva universal das canções nas sociedades humanas de todas as épocas e lugares; o papel importante e constante que a tradução desempenha no campo da música vocal, com uma presença normalmente subestimada. Responde a questões introdutórias previsíveis dos leitores. Formula a concepção de tradução adotada: "transferência interlingual de conteúdo - especialmente do sentido (meaning) -, de uma língua a outra", reconhecendo-a como "relativamente estreita, contudo comum no campo profissional da tradução". Explica como será usado o termo "letra de canção" (song-lyrics): "um termo guarda-chuva para qualquer texto cantado em qualquer música vocal”. Destaca duas características da tradução de canções: (1) a variedade de propósitos possíveis; (2) as restrições rígidas impostas em um desses propósitos, que é elaborar uma tradução cantável. Aponta a amplitude do campo da tradução de canções e apresenta uma terminologia básica: canções estróficas, refrão, melisma, configuração silábica, e as noções de dois pólos num gradiente ao longo do qual as diversas canções se situam: prevalência da palavra (logocêntricas) e prevalência da música (musicocêntricas). Traz uma síntese da trajetória pessoal do autor, no contato com canções e suas traduções.

Cap. 2, "Looking closely at the source text". Começa com linhas gerais de diferenciação entre letras de canção e poemas, e focaliza os "problemas de sentido" mais típicos que uma letra de canção pode apresentar na primeira fase do proceso tradutório: a compreensão do texto-fonte. "Sentido" (Sense, com maiúscula) é usado como termo que denota "questões semânticas que dominam as discussões sobre tradução de não-ficção: significado (meaning), conteúdo e intenção". Discutem-se colocados inusitados (ex. "nowhere man”), alusões culturais, usos não padrão da língua (dialeto, socioleto, gíria, coloquialismos); questões culturais; "outros 
problemas, em ordem alfabética" (ambiguidade; arcaísmos e linguagem fora de uso); eufemismos e linguagem indireta; expressões fixas e fraseologias estrangeiras; ironia; humor, piadas e trocadilhos; metáforas e símiles; neologismos (novas palavras e fraseologias inventadas); repetições; rimas; vulgaridade e obscenidade. A consideração de que cada língua tem suas peculiaridades é exemplificada numa subdivisão sobre particularidades da língua inglesa. Por fim, discute se há canções "intraduzíveis".

Cap. 3, "Translations to read". Explora as especificidades da tradução de letras de canção para diferentes propósitos, tendo em mente a Teoria do Skopos (palavra do grego que significa "propósito" ou "finalidade"). A tradução de uma letra de canção pode ser requerida para finalidades variadas, diferentes da de ser cantada. As seguintes finalidades "não cantáveis" são o foco do capítulo: tradução para estudo, tradução para um programa impresso, para um encarte de $C D$, para legendagem ou supralegendagem, para uma introdução falada. Desenvolve-se cada uma delas, tratando de suas prioridades, tipos de tradução e estratégias.

Cap. 4, “'Downstream' difficulties”. Ocupa-se de desafios na fase final do processo tradutório: reformular a letra na língua-alvo. Parte da metáfora da tradução como viagem marítima em que um texto-fonte é transportado a outro país, por um oceano por vezes turbulento, chegando ao porto estrangeiro com itens perdidos na travessia: vogais, consoantes, elementos morfossintáticos, extensão em sílabas, precisão e completude dos significados. A tarefa do tradutor não seria garantir a sobrevivência de cada item do carregamento (tarefa impossível), mas distinguir os mais valiosos e priorizar a preservação deles, mesmo que a expensas de outros. Na canção, tal discernimento seria mais complexo do que num texto em que a informação é o principal a preservar, pois frequentemente são valiosos elementos como os sons e o tom das palavras (afetivo, sarcástico etc.). Especial importância é atribuída à naturalidade, definida como "observar as normas da língua-alvo" (p. 65). Discutem-se: registro, usos criativos da língua, a alternativa entre tradução domesticadora ou estrangeirizadora, e se seria preferível cantar canções na língua original ou em traduções, e quando. 
Cap. 5, "Singable translations (A) - like a pentathlon". Começa a tratar das características que tornam a finalidade "ser cantável" a mais desafiadora, por requer atenção a fatores adicionais, em decorrência da sincronia com a música preexistente. A maioria das questões poderia ser agrupada em cinco quesitos: cantabilidade, sentido (Sense), naturalidade, ritmo e rima. Uma boa tradução cantável atingiria um equilíbrio ótimo no conjunto dos cinco. Faz-se uma analogia com o pentatlo, em que o atleta vencedor é quem consegue a melhor pontuação na somatória de desempenho em cinco modalidades esportivas díspares entre si. 0 capítulo desenvolve os três primeiros quesitos do "pentatlo"; dá quatro dicas iniciais para a tradução cantável; aponta técnicas adicionais importantes para a "caixa de ferramentas" na tradução de canção (ex. compensação e sinonímia próxima).

Cap. 6, "Singable translations (B) - rhythm and rhyme". Desenvolve os dois últimos quesitos da tradução cantável: ritmo e rima. Diferencia-se o ritmo da música do ritmo da palavra falada: a música preexistente tem batidas, compassos e duração de notas. Esses são os aspectos do "ritmo" tratados. A abordagem do pentlato sugere cuidado com decisões sobre a importância da rima, propondo: formas de estimar seu peso; tratá-las com margem de flexibilidade; táticas para conseguir equilíbrio com outros quesitos (como sentido e ritmo), em favor da qualidade do conjunto. 0 final do capítulo é dedicado a como adequar o pentlato da tradução cantável para atender requisitos adicionais de eficácia para gêneros dramáticos.

Cap. 7, "The place of adaptations". Defende a necessidade de ser fiel ao texto-fonte em muitos aspectos, incluída a transferência do sentido (meaning), para poder chamar propriamente uma canção de "tradução". Propõe definições de tradução e adaptação operacionais para esse campo, que ajudem a distinguir uma letra traduzida de uma letra adaptada, a partir do sentido, entendido como significado verbal. Defende a importância da distinção, e de não apresentar adaptações como traduções, com argumentos de natureza ética, de respeito aos autores e ao público, além de questões legais de propriedade intelectual. Há um parêntese para discutir o caso da substituição de texto (replacement text): casos em que as palavras não mostram qualquer transferência semântica com relação o texto-fonte, ainda 
que se ajustem perfeitamente à mesma música preexistente. 0 final é dedicado às adaptações, em torno de exame de casos. 0 autor assume para sua prática posição em favor do "paradigma da fidelidade", em contraposição com o "paradigma da adaptação": "para adaptar uma canção, primeiro tente traduzir, e, se falhar nisso, transforme o rascunho da sua tradução numa adaptação que funcione bem na língua-alvo" (p. 121).

A riqueza de exemplos beneficia muito o livro. A proposta é assumidamente prescritiva, articulada em torno de uma definição de tradução restrita explicitada desde primeiras páginas, e, de acordo com isso, é uma proposta bem realizada. Eventuais questionamentos que possam surgir não diminuem seu interesse também para pesquisadores. Translating Song é um livro relevante para quem se interessa pela tradução de canções, por diversas razões. A proposta do pentatlo inclui aspectos musicais e fornece um instrumental produtivo para a metodologia de pesquisa de tradução cantável de canções. Já vem sendo aplicada assim. Peter Low tem um lugar de pioneirismo nas publicações sobre tradução de canção, ao lado dos principais autores aos quais remete nas bibliografias dos capítulos, de modo que são fornecidas também ótimas referências sobre o tema ${ }^{3}$. Creio que poucos poderiam fazer atualmente um livro autoral tão abrangente com uma proposta original bem elaborada e detalhada para a prática tradução de canção, resultado de mais de uma década de trabalho do autor com o tema. É uma publicação bem-vinda para estudantes, tradutores, professores e pesquisadores no campo.

\section{Referências bibliográficas}

GORLÉE, D. (ed.) Song and Significance. Virtues and Vices of Vocal Translation. Amsterdam/New York: Rodopi, 2005.

Susam-Sarajeva, S. (ed.) The Translator, v. 14 n. 2, Special Issue: Translation and Music, 2008.

\footnotetext{
${ }^{3}$ Para esse interesse, uma ampla lista de referências bibliográficas está disponível página web do Translating Music project, dirigido por Lucile Desblache, no endereço: http://www.translatingmusic.com/styled-7/styled-16/index.html
} 